\title{
UAV AND GIS BASED TOOL FOR COLLECTION AND PROPAGATION OF SEEDS MATERIAL - FIRST RESULTS
}

\author{
K. Stereńczak, P. Mroczek, S. Jastrzębowski, G. Krok, M. Lisańczuk, M. Klisz, W. Kantorowicz
}

Forest Research Institute, Department of Forest Resources Management Sekocin Stary, ul. Braci Leśnej 3, 05-090 Raszyn, Poland.

(k.sterenczak, p.mroczek, s.jastrzebowski, g.krok, m.lisanczuk, m.klisz, w.kantonowicz)@ibles.waw.pl

\section{Commission VIII, WG VIII/7}

\section{KEY WORDS: Seed Stands, Forests, DSS, UAV}

\begin{abstract}
:
Seed management carried out by The State Forests National Forest Holding is an integral part of rational forest management. Seed collection takes place mainly from stands belonging to first category of forest reproductive material, which is the largest seed base in Poland. In smaller amount, seeds are collected in selective objects of highest forest reproductive material category (selected seed stands, seed orchards). The previous estimation methods of seed crop were based on visual assessment of cones in the stands for their harvest. Following the rules of FRM transfer is additional difficulty of rational seed management which limits the possibility of the use of planting material in Poland.

Statements concerning forecast of seed crop and monitoring of seed quality is based on annual reports from the State Forest Service. Forest Research Institute is responsible for preparing and publishing above-mentioned statements. A small extent of its automatization and optimization is a large disadvantage of this procedure. In order to make this process more effective web-based GIS application was designed. Its main performance will give a possibility to upload present-day information on seed efficiency, their spatial pattern and availability. Currently this system is under preparation.

As a result, the project team will get a possibility to increase participation of seed material collected from selected seed base and to share good practices on this issue in more efficient way. In the future this will make it possible to obtain greater genetic gain of selection strategy.

Additionally, first results presented in literature showed possible use of unmanned aerial system/vehicle (UAS/V) for supporting of seed crop forecast procedure.
\end{abstract}

\section{INTRODUCTION}

\subsection{Seed management in Poland}

Seed management run by foresters in Poland is based on visual estimation of seed crop and the current demand for seeds from the plan of forest renewal (Directive, 2011). Annual reports on expected level of seed crop are handled to Forest Research Institute (FRI). In questionnaires submitted from 2005 by the Internet, forest inspectorates provide the following information on seed crop of Scots pine (Pinus sylvestris), Norway spruce (Picea abies), Silver fir (Abies alba), Larch sp. (Larix), Oaks (from 2008 separately for pedunculate (Quercus robur) and sessile (Quercus petreae) oaks and European beech (Fagus sylvatica) in production seed stands and selected seed stands (Program, 2011): verified information about seed crop magnitude in previous year, weight of cones/seed collected in previous year (or both). Additionally, forest inspectorates provide forecast for expected magnitude of seed crop in current year based on immature cones and fruit, expected collection of cones/seed in current year (weight in kilograms), requirements for previous year and summary area of seed stands, seed orchards and seedling seed orchards. In relation to the percentage of fruiting trees, 4 levels of seed fertility are distinguished:

- $\quad$ lack of fertility - the lack of trees fruiting abundantly enough in relation to economic viability,

- poor fertility - only single trees, on the stand edges, fruiting,
- $\quad$ medium fertility - small number of trees, on the stand edges and small percentage inside the stand, fruiting,

- $\quad$ good fertility - large number of trees fruiting.

In the evaluation of stands and plantations it is assumed that particular degrees of fertility are equivalent to the following percentage of the full fertility: no fertility -0 , poor -10 , medium - 30 and good fertility $-100 \%$. The calculations assume the average productivity of seeds from cones for pine 1.5; spruce - 2.5; larch - 5.0; fir - 14.0; Douglas fir - 2.0; black pine 3.0; black alder - 10.0; wild cherry - 15.0 and black locust - 25.0\%. On this information, FRI develops collective report, which presents the projected seed crop for all the major forest species as well as its intensity. Data provided in the report allow the identification of areas of the country where seed deficit of the selected species is expected. On this basis, decisions on joining the collection or use seed stocks warehoused in storages or regional gene banks are made. In case of small-seeded species (pine, spruce) and some large-seeded species (beech) is not an issue because its seed can be stored for long time. But in case of oak trees with abundant seed years taking place every 68 years, and the seeds which belong to the category of "orthodox" (they cannot be stored for more than two years) this may be a serious problem to ensure the right amount of seedlings for afforestation and reforestation (Kantorowicz, 2000).

Seed regionalization might be another difficulty. This important legal regulation from the point of view of conservation of genetic resources appears to be a major barrier in obtaining seeds, particularly from outside of the maternal seed region. 
In presented study the project team introduces conception of DSS WebGIS based tool to optimize seed management. Another aim of the paper is to test possibility of use Unmanned Aerial Vehicle (UAV) in seed crop estimation.

\subsection{DSS system design}

Statements on seed crop forecast and monitoring of seeding and seed quality is based on annual reports from State Forest Service. Forest Research Institute is responsible for preparing and publishing this statements. A small extent of its automatization and optimization is a large disadvantage of this procedure. The estimation methods of seed crop is based on visual assessment of cones in the stands for their harvest.

WebGIS based Decision Support System is a prototype system based on Forest Digital Maps - standard forest maps in Poland, covering the state-owned forests belonging to The State Forests National Forest Holding (SFNFH). SFNFH manages stateowned forests on behalf of the Polish State Treasury on 7500000 ha which stands for more than $82 \%$ of the whole forest area in Poland (9 100000 ha) (WWW 1). The main aim of DSS is to optimize the workflow of gathering information from estimated quantities of cones by uploading current information about seed efficiency, its spatial distribution and availability throughout working online WebGIS. The portal is prepared mainly for foresters for nursery who having logged in the system - receive complete information on the availability of forest reproductive material both for the areas of Forest Management and the regions of origin.

In the first stage of the project the portal will bring complete information about the current harvest spruce seeds for the selected seed regions. In the course of the development of the portal it is planned to take into account the rest of the main species that grow in Poland.

There are 4 main parts of the system (Figure 1):

1. Geo-data - Digital Forest Maps with stand and seed region borders, UAV images optionally,

2. Web forms for reports from forecast seed crop, control of the material and information about available seed kilograms from specified stands,

3. WebGIS server for managing the spatial data with possibility to interact with the geodatabase in order to optimise seed material exchange,

4. Users - foresters.

Having completed the field/UAV based seed crop estimation, results will be transferred into the system which gives information on expected amount $(\mathrm{kg})$ of the seeds from the stand. After collection of cones, their samples are sent for seed productivity assessment. Its results will update previous estimation and give real information about available amount of seed on the stand level. Thanks to that information the rest of users could fill the orders for seeds on a given species online. The information about the weight of seeds for a given species will be dynamically displayed on the map. In case of ordering the material a user would have to fulfil web form. Afterwards foresters could organize the process of harvesting the cones from trees in a more economical way by selecting the most cropped stands, with possibility to monitor the seed arability on the stand level in real time. As a result of the organization of the collecting the cones a manager will be able to concentrate only on those areas which prove cost-effective collection.

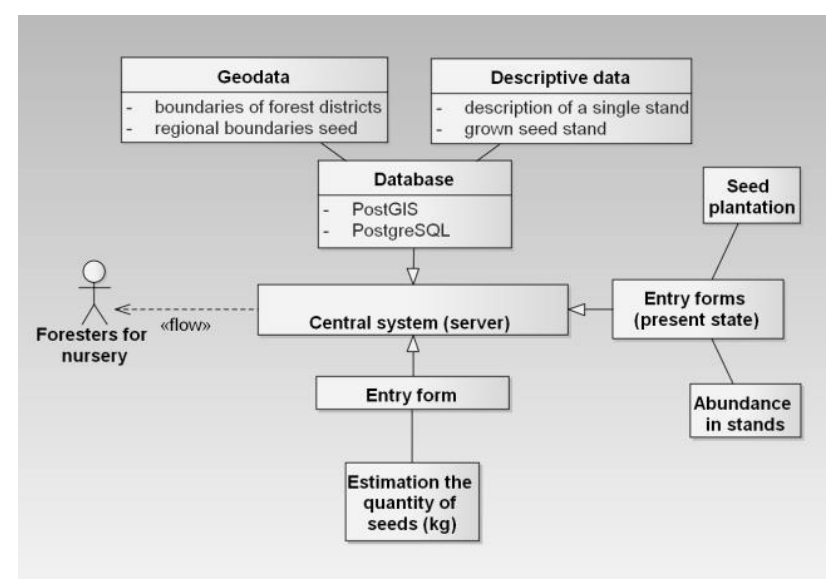

Figure 1. Basic WebGIS based portal architecture

\subsection{UAV}

History teaches us that war is a powerhouse for the development of most technologies. This is also true for the history of unmanned aerial vehicles (UAVs). Development of the first modern, unmanned aerial vehicles started soon after the advent of the airplane. The First World War demonstrated the potential of aerial reconnaissance conducted by the first UAVs (Blom, 2010).

Nevertheless, the idea of the use of such solutions for general purposes appeared approximately 2500 years ago in ancient Greece. Archytas from the city of Tarantas is considered the father of the first known independent flying construction. $\mathrm{He}$ built a mechanical bird called 'the pigeon', which was constructed out of the wood and had a steam propulsion attached in its stomach. Allegedly that bird flew about $200 \mathrm{~m}$ before failing to the ground (Valavanis, et al. 2007).

Over the past 15 years UAVs have evolved rapidly mainly for military purposes but also due to their more common utilization among civilian users. Precision GPS/INS systems allow for precise planning and executing of flight missions. Equipped with different kinds of sensors like digital cameras and/or LiDAR systems, UAVs are applied for scientific purposes in the field like: earth sensing, reconnaissance, environmental data collection and many other domains (Watts AC, et al. 2012).

High temporal resolution and relatively low costs of applications in comparison to satellite imagery and conventional airborne data sources make a place for UAV applications for forestry and agriculture purposes (Grenzdörffer, et al. 2008). For instance, these systems may be used in forestry for (Horcher and Visser, 2004):

- Monitoring of natural forests,

- Locating harvest sites and inspecting forestry operations,

- Forest fire detection,

- Determination of the biomass and crop growth.

Unmanned Aerial Vehicle could be one of the possible tools to support seed crop forecast with probability to replace most of human activity in that field with better accuracy and wider spatial perspective. UAV gives better view on the crown of a tree, especially in difficult areas and can help better estimate of spatial seeds cover. In this paper different perspective of Unmanned Aerial Vehicle imagery acquisition and its influence on detecting tree cones are examined by the team. 


\section{MATERIALS AND METHODS}

Data for this research was acquired for Norway Spruce (Picea Abies L.) stand on 13 April 2016. The flight was carried out on the forest compartment in Masovian District, Poland (Jabłonna Forest Inspectorate (Figure 2), N52³0'3.99”, E2046'11.91”).

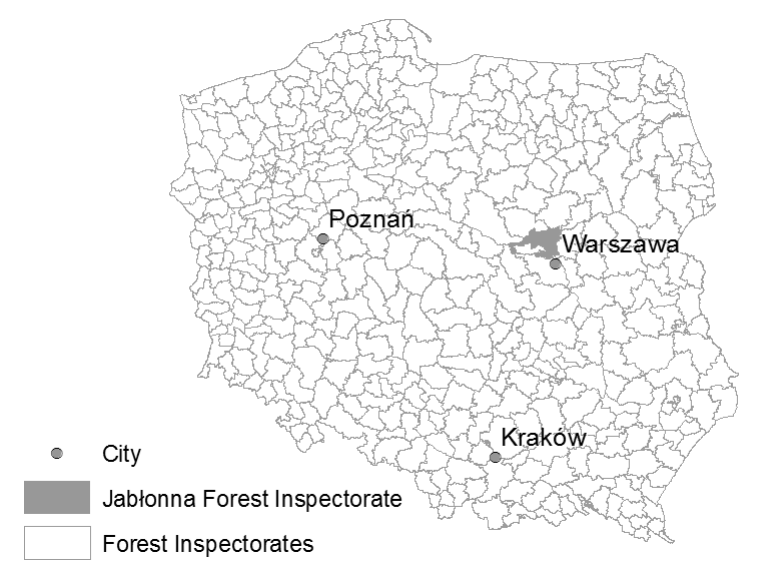

Figure 2. Location of the study area.

Data was collected by Quadrocopter DJI Phantom 3 with mounted the standard DJI RGB 12-megapixel camera. Images were acquired in three different perspectives: side images, diagonal images, pseudo-orthogonal images. The flight was carried out between 11:15 AM and 12:00 AM, the weather conditions were stable, overcast around $90 \%$, wind $2 \mathrm{~m} / \mathrm{s}$.

The analysis was based on visual interpretation of the images. Two operators (No 1 and No 2) counted the number of cones on tested tree for each image perspectives. All of the cones observed by the operators were counted. Even that, cones partly spotted were taken into consideration. Additionally, advantages and disadvantages of interpretation and acquisition of images from different perspectives were described.

\section{RESULTS}

The reference number of cones on the tree was 470 , and an average number from results of two operators image interpretation was 460 and 479 respectively.

\subsection{Side images}

Side images (Figure 3) were acquired perpendicular to vertical tree axis on the height equal to middle height of the crown. The GSD for that images was $2-5 \mathrm{~cm}$ in the nadir (depends on the distance between the UAV and the tested tree). UAV operator took pictures from 3 sides of the tree. The cones were counted for each image. Based on side images the number of cones counted for one tree is as follows:

$$
\begin{array}{ll}
\text { - } & 1^{\text {st }} \text { side picture (operator No. } 1 \text { - } 304 \text { cones, } \\
& \text { operator No. } 2 \text { - } 303 \text { cones) } \\
\text { - } & 2^{\text {nd }} \text { side picture (No.1 - } 206 \text { cones, No. } 2 \text { - 216) } \\
\text { - } & 3^{\text {rd }} \text { side picture (No. } 1 \text { - } 200 \text { cones, No. } 2 \text { - 203) }
\end{array}
$$

On average 239 cones were seen on 3 images interpreted by 2 operators, which gives about $51 \%$ of reference number of cones. We reflect following advantages of side image acquisition and interpretation:

- Very good visibility of the cones,

- Possibility to acquire images along full tree crown (high possibility to detect every single cone)

- Accurate method to count cones on single tree level,
- Small GSD variation (depends on the possibility to fly between aircraft and the tested tree which influences the distance)

On the other hand, the following disadvantages were outlined:

- Flight between crowns of a single tree is difficult, even dangerous, and limited by canopy closure, undergrowth and forest density (only selected tree in the stand can be photographed),

- High risk of producing error while calculating the cones - possibility to count cones doubly or triply,

- Problem with counting cones which are in the form of bunch (e.g. overlapping cones),

- Image quality and interpretability highly depend on exposition of the tree (shadows),

- UAV operator is permanently involved in pilotage,

- Image acquisition is carried out in the manual mode.

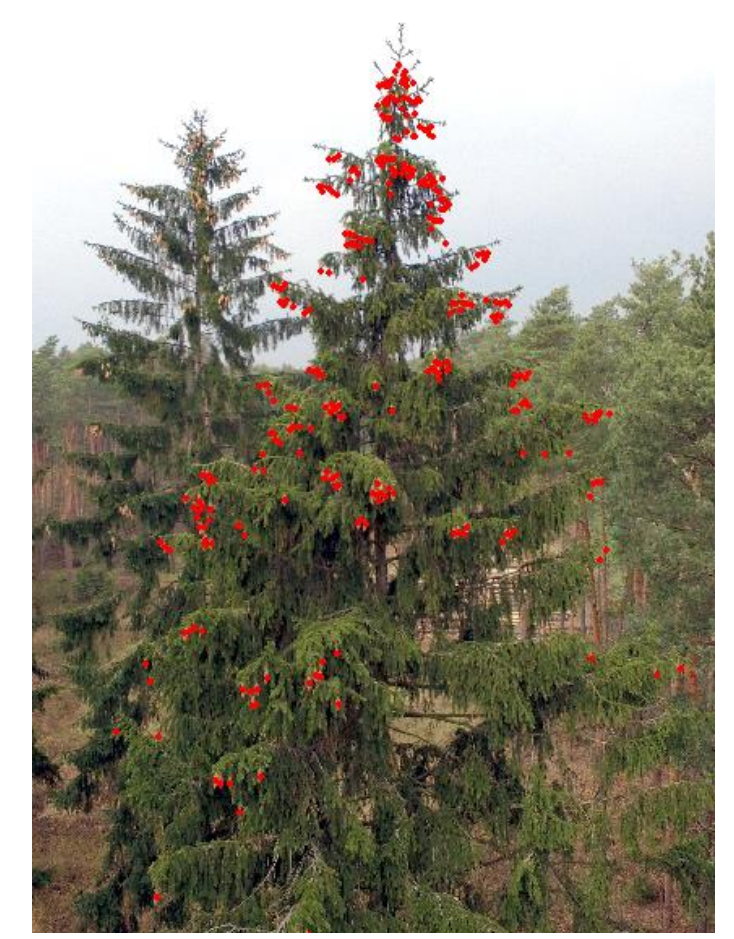

Figure 3. Side image (red dots symbolize counted cones).

\subsection{Diagonal images}

Diagonal image (Figure 4) was acquired from the above of tree height with off-nadir angel between $25^{\circ}$ to $35^{\circ}$. Counting cones on that 3 side images gave the following results:

- $\quad 1^{\text {st }}$ side image represents by No $1-283$ cones No 2 279 cones,

- $\quad 2^{\text {nd }}$ side image represents by 190 cones, 197 ,

- $\quad 3^{\text {rd }}$ side image represents by 217 cones, 220.

On average 231 cones were seen on 3 images interpreted by 2 operators, which gives approximately $49 \%$ of reference number of cones.

Advantages of such solutions are as follows:

- Good visibility of cones,

- Possibility to count cones for more than one tree,

- Flight is safer and easier than side image acquisition,

- UAV operator has to be involved in data acquisition much less than performing side images. It is easier to fly over the crowns. 
- It is possible to plan flight mission and automate Disadvantages are as follow:

- Cones from the lower part of the crown are not visible,

- Visibility of the cones is limited based on the image angle (larger of-nadir acquisition cause larger crown overlapping and lover single crown visibility because of shadows effect), canopy closure, undergrowth and forest density,

- Image quality and interpretability highly depend on exposition of the tree (shadows),

- $\quad$ Flight plan for whole is difficult and can cause varied GSD variations,

- Significantly smaller tree inside the stand cannot be photographed,

- Cones located near the trunk are not well visible which generates the problem in counting.

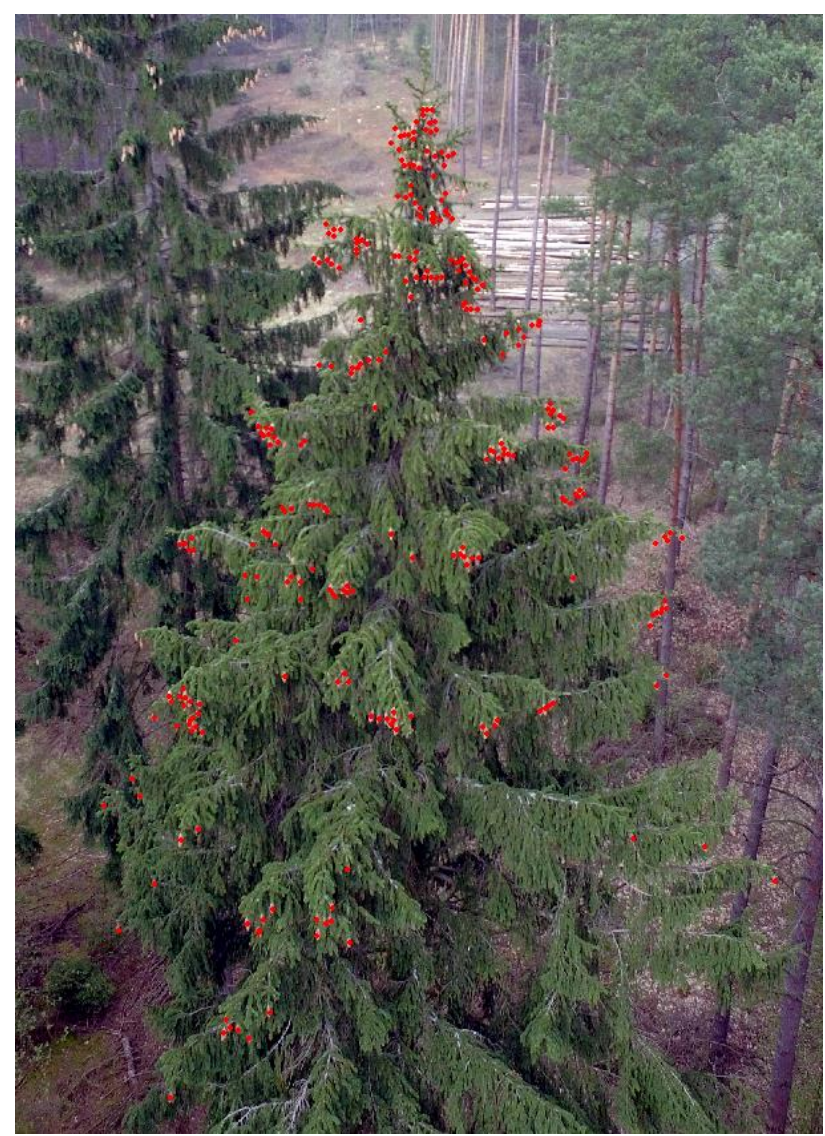

Figure 4. An example of diagonal image (red dots symbolize counted cones).

\subsection{Orthogonal images}

Two orthogonal image (Figure 5) were acquired from above of the tested tree. The results of its interpretation done by two operators are as follows:

$$
\begin{aligned}
& 1^{\text {st }} \text { orthogonal image No. } 1-216 \text { cones, } \\
& \text { No. } 2-213 \text { cones } \\
& 2^{\text {nd }} \text { orthogonal image No. } 1-142 \text {, No. } 2-139 .
\end{aligned}
$$

On average 178 cones were seen on 2 images interpreted by 2 operators, which gives approximately $38 \%$ of reference number of cones.

Advantages of such solution are as follow:

- Flight is safer than other above mentioned methods,
- Flight plan can be prepared in automatic or semiautomatic way,

- Pilot has to be involved, but his involvement is the smallest among above mentioned methods,

- $\quad$ GSD can be planned

Disadvantages are as follows:

- Very poor visibility of the cones (impossible for accurate count) -correlation between what we see and what is on the tree should be developed,

- Image quality and interpretability highly depend on exposition of the tree (shadows),

- Cones from the lower part of the crown are not visible,

- Motion blur parameter can change rapidly by the wind which produces blurry photos.

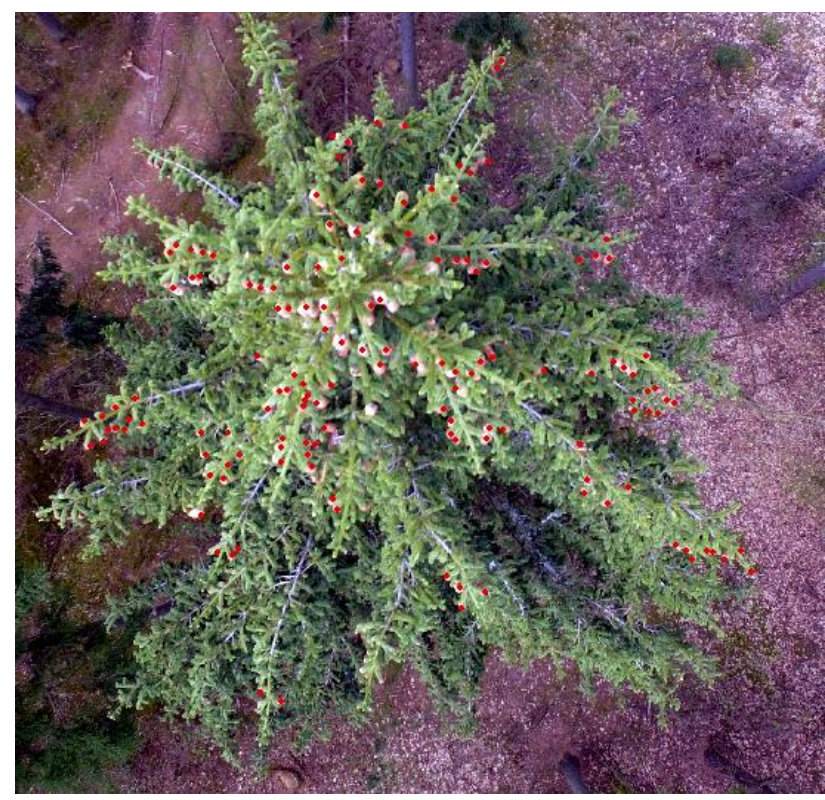

Figure 5. Orthogonal image.

\section{DISCUSSION AND CONCLUSIONS}

Based on that experience the project team concludes that UAV images could be used to estimate the number of cones for a single tree. Unique photos were tested for single tree and it occurred that it is possible to detect and count single spruce cones. The experience showed that the final results depend on a proper angle shooting of the picture, the distance between the studied tree and the aircraft with mounted camera as well as weather condition. It occurred that insolation plays a crucial role. High solar activity reflects the light from cones which disturbs the quality of an image (lighten cones in bunches cannot be detect). Additionally, stand variables and tree shape varied a lot, which makes large variability on the observed number of cones even for one selected tree.

Orthogonal images showed that the motion blur parameter plays a crucial role for the requirement of counting the cones. Also, a resolution of the image is significant as it is easy to detect even a part of a given cone. To sum up, a good quality image is indispensable otherwise it is difficult to qualify partially visible cones.

Based on that experience it was noticed that in dense forest diagonal image is the most useful approach. Moreover, in order to automate the process, an operator can run flight mission and investigate larger area. 
GSD is very important as it can distinguish even partly seen cones which grow in bunches. But GSD is varied for single image and that is why planning of the mission is a crucial and difficult issue.

According to the results gathered from counting the cones from side images, diagonal images and orthogonal image it is easy to notice that higher number of cones were detected on side images. Unfortunately, this approach to the subject is possible to implement only for single tree or really sparse spruce stand. By analysing gathered result it is stated that diagonal images are the best options for stands as operator can plan mission flight and later on making image mosaicking; there is a possibility to detect cones for the whole stand not just single tree. It is also possible to develop an algorithm which is based on the number of cones from different images and estimate the number of cones for the whole tree.

This experiment with UAV and one tree shows only large number of variables which have to be taken into account in future research. Future much deeper study will have to be carried out to define a relationship between number of seen cones on specified image and a reference number of cones.

\section{ACKNOWLEDGEMENTS}

This work is supported by project no 240243 titled "The use of the DSS in estimating the yield of cones on spruce (Picea abies)", ("Wykorzystanie BSL w szacowaniu urodzaju szyszek świerka pospolitego") funded by Forest Research Institute.

Authors would like to express appreciation to Michał Sosnowski for English correction of the manuscript.

\section{REFERENCES}

Blom, J., 2010. Unmanned Aerial System: A Historical Perspective. Combat Studies Institute Press: 45 pp.

Directive, 2011. Zarządzenie Nr 33 Dyrektora Generalnego Lasów Państwowych z dnia 5 sierpnia 2011 r. w sprawie organizacji i dokonywania oceny nasion w Państwowym Gospodarstwie Leśnym Lasy Państwowe.

Grenzdörffer, G.J., Engel, A., Teichert, B., 2008. The Photogrammetric Potential of Low-Cost UAVs In Forestry and Agriculture. The International Archives of the Photogrammetry, Remote Sensing and Spatial Information Sciences, XXXVII (B1), pp. 1207-1213.

Horcher, A., Visser, R.J.M., 2004. Unmanned Aerial Vehicles: Applications for Natural Resource Management and Monitoring. Council on Forest Engineering Annual Meeting. Hot Springs (AR), USA, 2004.

Kantorowicz, W., 2000. Half a century of seeds years in major tree species of Poland. Silvae Genetica, 49(6), pp. 245-249.

Program, 2011. Program of conserving forest genetic resources and breeding of trees in Poland for the years $2011-2035$. CILP, Warsaw, 2011.

Valavanis, K.P., Vachtsevanos, G.J., Antsaklis, P.J., 2007. Technology and autonomous mechanisms in the mediterranean: From ancient greece to byzantium. In: Proc. European Control Conference (ECC 2007), Kos, Greece, pp. 263-270.

Watts, A.C., Ambrosia, V.G., Hinkley, E.A., 2012. Unmanned Aircraft Systems in Remote Sensing and Scientific Research:
Classification and Considerations of Use. Remote Sensing, 4(6), pp. 1671-1692.

WWW 1 - http://www.lasy.gov.pl/publikacje/in-english, acquired April, 6 $6^{\text {th }} 2016$. 